\title{
Optimization of Management Information Support as a Basis for Organizational Transformations at an Enterprise
}

\author{
Valentyna Kyriy $^{1}$, Iryna Sheiko ${ }^{1}$, Roksana Petrova ${ }^{1}$ \\ ${ }^{1}$ Department of Economic Cybernetics and Economic Security Management, \\ Kharkiv National University of Radioelectronics, Kharkiv, Ukraine
}

\section{Article Info}

Received Jab 27, 2019

\section{Keyword:}

Information flow

Document

Optimization

Petri Net

Division Transformation

\begin{abstract}
Increasing of information flows cause the necessity of optimizing their quantity, structure and distribution. In order to eliminate the disadvantages inherent in information systems of electricity delivery enterprises for the processing of internal information, a methodical approach to optimizing document circulation on the basis of modeling with the help of Petri Nets is developed. This article presents a systematic methodology for modeling document circulation flows at enterprise. The constructed model allows to form the structure of the system and the processes taking place in it, to analyze the static state of the system of document circulation and the dynamics of information flows. Also, we described mathematical model of document circulation process, where the central place is occupied by identification and removing of duplicate documents and those that are not processed at each stage of their moving. At final stage we propose to distribute information flows due to specificity of division. For this we need to define and assign information functions to divisions and formalize them considering the rules for processing documents. To determine the extent to which the processing rules of the documents actually go in the subdivision of its main for each transition we introduce the measure of its specificity for subsystem.
\end{abstract}

\section{Corresponding Author:}

Iryna Sheiko,

Department of Economic Cybernetics and Economic Security Management,

Kharkiv National University of Radioelectronics,

Nauky Ave. 14, 61166, Kharkiv,Ukraine.

Email: irina.sheiko@nure.ua

\section{Introduction}

The level and completeness of information support defines the efficiency of management of enterprise production and economic processes, the ability to operate in difficult economic conditions.

Nowadays the volume of information flows, as within the enterprise and in relations with the external business environment, is increasing sharply. So, the intensity of information exchange is high. This also applies to the energy sector, where volumes of data relevant to price formation, technological losses of energy, factors of competition in the electricity market and energy services, increased. Not speaking already about traditional information flows regarding the formation of electricity power balances, operational management of transmission of electricity power.

The simultaneity of electricity production and consumption processes leads to requirements of effective planning, based on available information and the complexity of information communications of power companies with the external environment. The number of monitored internal indicators of activity provides a significant weight to the information support of energy companies. But the permanent changes, that are taking 
place in enterprises, mainly affect the information security negativly: the circulation of documents is numerous and varied, and it also happens chaotic. In particular, such situation is inherent in energy distribution business, where the volume of economic information is much higher than at other stages of energy production.

The analysis of information exchange in all functional areas of activity defined the main properties of document formation in energy companies: the insufficient use of the method of drawing up documents at the enterprise is the main reason for the presence of a large number of documents in circulation; one of the main factors in creating documents is the requests of external users - customers; there are significant disadvantages of marketing information provision of energy-saving activities. With the general functional orientation of the document formation a significant disadvantages in the information flows exchange were defined: a considerable amount of duplicate information, its non-structured character, poor usage of contemporary computer applications of document creation in everyday work. Some of such defects can not be eliminated on their own, because existent document circulation model is associated with the formation of sectoral reporting. All received information requires registration, evaluation of its adequacy and correct definition of the final recipient, that is, in optimizing information flows. Enterprises, including energy companies, do not want to spend money on sending by communication channels excessive information and receive the same data. Thus, organizations try to avoid duplication of information in order to increase the efficiency of their activities. The solution to this problem lies in the optimization of information flows.

Modeling information flows for organizations is a very important and challenging task. In the processes of communication and information exchange within the organization involved different groups, processes, individuals, communication channels, etc. That is why the correct organization of information flows can increase the productivity of staff, accelerate decision-making and reduce the probability of errors.

This article devoted to the issues of modeling information flows of an organization, taking into account information links between departments.

\section{Material and methods}

Information flow effectiveness and optimization are catching eyes for many researchers and the study about them is valuable. There are a lot of approaches for modelling information flows. To model information flows means describing how information is transferred, changed, distributed [1]. Baldan described information flow policies [2], P.P. Sengupta et al. made comparative analysis of Economic and environmental performances in manufacturing industries [3], at [4] a cyber-physical systems approach to cognitive enterprise was described [4] Babenko investigated the process of multi-level management of enterprise production activities [5,6].

Although information processes are subject to the general purpose of the enterprise, but at their final implementation are not subordinate to strict functional dependence, their modelling should be done by statistical methods or methods of simulation. For economic systems with a multiple control parameters, logical rules of operation, the need for varying degree of detailization, simulation models are used. The most fully such requirements correspond to simulation models as Petri Nets [7,8,9]. Petri Nets are widely used for modelling socio-economic processess: Cheng et al. used Petri Nets for resourse management in building design process [10], also they were used in modeling of energy consumption [11,12,13], in planning of construction projects [14], modelling of flexible manufacturing sytems [15], modeling discrete event process [16], at resource allocation [17], in assesing of information security risk [18], in dynamic programming scheduling [19] simulation for small and medium enterprises [20], production logistics and supply chain system[21], stochastic behaviour analysis of industrial system [22] accounting information system [23], control of production task flows [24], reverse-engineering cycles [25], real-time operation planning system in distributed manufacturing network [26],in supply chain finance business process [27], in integrating system dynamics [28], for integrating purchasing, production and packaging for Kanban system [29], in safety analysis of production systems [30], to verify BPMN Models [31]. D.A. Karras et al.[32] analysed different approaches to model competition analysis and among them described Petri Nets.

Petri's theory of networks enables modeling of the system by presenting it as a two-tone oriented graph. The graph analysis allows to obtain important information about the structure and dynamical behavior of the simulated system $[7,8,9,33]$. The graphical structure model of Petri nets consists of nodes and arcs. Also node set includes two independent subsets, place set $P=\left\{p_{1}, p_{2}, \ldots, p_{n}\right\}$, and transition set $T=\left\{t_{1}, t_{2}, \ldots, t_{n}\right\}$. 
Each node corresponds to only one place element $p_{i}$ that represent the status of some components of the system or transition element $t_{i}$ that defines dynamics of the system. Two different kinds of weighted directional arcs are included in arc set, which are named as the subset of input arcs and the one of output arcs $[7,8,9,33]$.

\section{Results and Discussion}

There are several potential ways of practical application of Petri Networks when designing and analyzing systems. In our study, Petri's networks are considered as an auxiliary analysis and synthesis tool. At first, the system is simulated by Petri's network, and then the constructed model is analyzed in order to optimize information processes. Simulating of information processes using Petri Networks consists several stages: determination of the elements of the model - organizational structure of the enterprise, documents, rules of operation of the model; determinations of main operations of processing, movement and storage of documents in structural units / departments; using results of simulation to optimize document circulation.

In order to eliminate the disadvantages inherent in information systems of electricity delivery enterprises for the processing of internal information, a methodical approach to optimize internal document circulation on the basis of Petri Nets modeling was developed. The constructed model allows to form the structure of the system and the processes taking place in it, to analyze the static state of the system of document circulation and the dynamics of information flows. This model consists three main stages:

1. Each document that functions in the document flow system is presented in the form of the Petri network place and is both an integral object and a specially organized structure of the set of indicators. All processing of documents is considered by means of two constructive operations - analysis and synthesis. The analysis involves the decomposition of the document in accordance with the rules for the components for its further transformations. Synthesis means the construction of documents according to certain rules from the set of existing information indicators. All transactions with documents that are carried out in one organizational unit are proposed to be merged into the macro-switch of the Petri network. Incoming labels for such a move will be documents that arrive in the unit, and the results of such a transition are output documents.

2. On the basis of the formal description of operations (transitions) over documents (macros of the Petri network) the system of document circulation is analyzed. An analysis of a simulated matrix, which reflects the process of processing documents in the enterprise division, identifies duplicate documents and those that are not processed at each stage of their moving.

3. The reorganization of the document flow model occurs in the process of duplicate documents or indicators eliminating and reallocating information, that is not processed on the basis of formal rules, which reflect the functions and tasks of the relevant units of the enterprise.

Modeling of document circulation process at the enterprise should begin with the submission of the document - the main carrier of information in the system. In terms of Peter's theory of networks, the document model is a macromotum of $\mathrm{M}$. Any document is presented in the form of a set of indicators - the requisites characterizing the type of document, and the meaningful and / or computational indicators. Assume M document, and Mk - its k-th component, then the model of the document M can be submitted as a set:

$$
M=\left\{M_{1}, M_{2}, \ldots, M_{k}, \ldots, M_{q}\right\},
$$

where $\mathrm{q}$ is the number of components of the document.

All documents in management departments are processed using two constructive operations - analysis and synthesis.

The analysis of the document $\mathrm{M}$ is the decomposition of its constituent parts into different semantic or technical subsets of $\mathrm{SM}_{\mathrm{i}}$, where $\mathrm{i}$ varies from 1 to $\mathrm{r}$; and $\mathrm{r}$ is the number of parts of the former document, which are considered as separate units of information. For example, int is the document analysis operator, that is, the formalized rule of its expansion into parts, then the process of analysis of the document $\mathrm{M}$ can be presented as:

$$
\begin{aligned}
\mathrm{in}_{\mathrm{t}}(\mathrm{M}) & =\left(\mathrm{SM}^{1}, \mathrm{SM}^{2}, \ldots, \mathrm{SM}^{\mathrm{i}}, \ldots, \mathrm{SM}^{\mathrm{r}}\right) \\
\mathrm{SM}^{\mathrm{i}} & =\left\{\mathrm{M}_{\mathrm{i} 1}, \mathrm{M}_{\mathrm{i} 2}, \ldots, \mathrm{M}_{\mathrm{ij}}, \ldots, \mathrm{M}_{\mathrm{is}}\right\}
\end{aligned}
$$


where Mij - component $\mathrm{ij}$ of the document $\mathrm{M}, \mathrm{s}$ is the number of parts of the document $\mathrm{M}$, that are included in the new document.

Synthesis of document $\mathrm{M}$ is its creation by combining different constituents of other documents, which are presented as separate elements, $\mathrm{M}^{\mathrm{i}}$, where $\mathrm{i}$ varies from 1 to $\mathrm{r}$; and $\mathrm{r}$ is the number of documents or parts of documents processed in accordance with the rules $f_{i}(i=1, \ldots \ldots, r)$ for obtaining a document $M$. Let outt - the synthesis operator, which is a formalized rule for creating a document from a certain data array, then the process of document synthesis can be represented as:

$$
\begin{gathered}
{ }^{\text {out }} \mathrm{t}\left(\mathrm{M}^{1}, \mathrm{M}^{2}, \ldots, \mathrm{M}^{\mathrm{i}}, \ldots, \mathrm{M}^{\mathrm{r}}\right)=\mathrm{M}, \\
\mathrm{M}=\bigcup_{i=1}^{r} f_{i}\left(M^{i}\right) .
\end{gathered}
$$

In terms of the theory of Petri's networks, the analysis operation is an int crossing with one input arc corresponding to the input document, and $r$ the output arcs corresponding to the parts of the input document, which will continue to act as separate elements (Fig. 1 (a)), and the synthesis operation is passing outt with $r$ input arcs and one output arc (Fig. 1. (b)).
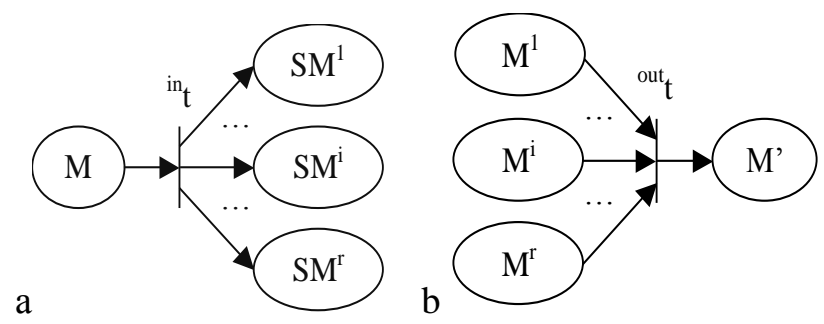

Figure 1. Operations of document analysis(a) and synthesis (b)

Working with multiple documents requires additional descriptions. The process of processing several documents in the department (work station) can formally be divided into two stages. At first, each document is analyzed, and then - the new document is created by synthesis of parts obtained at the analysis stage. Simulation of these stages will allow to build a model of the existing workflow in order to further optimize.

To simulate the process of analyzing multiple documents, we denote the incoming documents submitted for processing in the unit as: ${ }^{\text {in }} \mathrm{M}_{1},{ }^{\text {in }} \mathrm{M}_{2}, \ldots,{ }^{\text {in }} \mathrm{M}_{\mathrm{i}}, \ldots,{ }^{\text {in }} \mathrm{M}_{\mathrm{n}}$. According to the previous agreement, the ${ }^{\text {in }} \mathrm{M}_{\mathrm{i}}$ document model has the form:

$$
{ }^{\text {in }} M_{i}=\left\{{ }^{i n} M_{1}^{i},{ }^{i n} M_{2}^{i}, \ldots,{ }^{i n} M_{k}^{i}, \ldots,{ }^{i n} M_{q(i)}^{i}\right\},
$$

where ${ }^{\text {in }} M_{k}^{i}$ - component $k$ of ${ }^{\text {in }} M_{i}$ document $q(i)$ - quantity of components of ${ }^{\text {in }} M_{i}$ document.

Considering a document as a logical sum of components, each ${ }^{\text {in }} \mathrm{M}_{\mathrm{i}}$ document can be opposed by an analysis operator ${ }^{\mathrm{in}} \mathrm{t}_{\mathrm{i}}$, such as:

$$
{ }^{\mathrm{in}} \mathrm{t}_{\mathrm{i}}\left({ }^{\mathrm{in}} \mathrm{M}_{\mathrm{i}}\right)=\left({ }^{\mathrm{in}} \mathrm{SM}^{\mathrm{i} 1},{ }^{\mathrm{in}} \mathrm{SM}^{\mathrm{i} 2}, \ldots,{ }^{\mathrm{in}} \mathrm{SM}^{\mathrm{ij}}, \ldots,{ }^{\mathrm{in}} \mathrm{S} \mathrm{M}^{\mathrm{ir}(\mathrm{i})}\right),
$$

де ${ }^{\mathrm{in}} \mathrm{SM}^{\mathrm{ij}}$-subset $\mathrm{j}$ of the parts of a document ${ }^{\mathrm{in}} \mathrm{M}_{\mathrm{i}, \mathrm{r}}(\mathrm{i})$-quantity of such subsets of document ${ }^{\mathrm{in}} \mathrm{M}_{\mathrm{i}}$. Each component of the ${ }^{\text {in }} \mathrm{SM}^{\mathrm{ij}}$ document can be expanded to separate indicators due to formula (2). Describing the logical subsets of the document values obtained as a result of the analysis, the set ${ }^{\mathrm{in}} \mathrm{SM}^{\mathrm{ij}}$ can be presented as follows:

$$
{ }^{\mathrm{in}} S \mathrm{M}^{\mathrm{ij}}=\left\{{ }^{\mathrm{in}} \mathbf{M}_{\mathrm{j} 1}^{\mathrm{i} 1},{ }^{\mathrm{in}} \mathbf{M}_{\mathrm{j} 2}^{\mathrm{i}}, \ldots,{ }^{\mathrm{in}} \mathbf{M}_{\mathrm{jk}}^{\mathrm{i}}, \ldots,{ }^{\mathrm{in}} \mathbf{M}_{\mathrm{j} s(\mathrm{i})}^{\mathrm{i}}\right\},
$$

where ${ }^{\mathrm{in}} \mathrm{M}_{\mathrm{jk}}^{\mathrm{i}}$-component $\mathrm{jk}$ of ${ }^{\mathrm{in}} \mathrm{M}_{\mathrm{i}}$ document, $\mathrm{s}(\mathrm{i})$ - quantity of components (separate indicators) of document ${ }^{\text {in }} \mathrm{M}_{\mathrm{i}}$, that are included in ${ }^{\mathrm{in}} \mathrm{SM}^{\mathrm{ij}}$. 
Due to theory of Petri net $[15,18]$, a set of analysis operators for documents, that entering a department, is an input function for some transition that simulates the processing of documents in this department.

The result of the synthesis of documents in the enterprise departments is $m$ new documents: ${ }^{\text {out }} \mathrm{M}_{1},{ }^{\text {out }} \mathrm{M}_{2}, \ldots$, ${ }^{\text {out }} M_{\mathrm{i}}, \ldots,{ }^{\text {out }} \mathrm{M}_{\mathrm{m}}$. Each of them can be aligned with operator of synthesis ${ }^{\text {out }} \mathrm{t}_{\mathrm{i}}$ :

$$
\begin{gathered}
\left.{ }_{\mathrm{t}_{\mathrm{i}}}{ }^{\mathrm{in}} \mathrm{SM}^{\mathrm{j} 1, \mathrm{k} 1},{ }^{\mathrm{in}} \mathrm{SM}^{\mathrm{j} 2, \mathrm{k} 2}, \ldots,{ }^{\mathrm{in}} \mathrm{SM}^{\mathrm{j} s, \mathrm{ks}}, \ldots,{ }^{\mathrm{in}} \mathrm{SM}^{\mathrm{j}(\mathrm{i}(\mathrm{i}), \mathrm{kr}(\mathrm{i})}\right)={ }^{\text {out }} \mathrm{M}_{\mathrm{i}}, \\
{ }^{{ }^{\mathrm{out}} \mathrm{M}} \mathrm{M}_{\mathrm{i}}=\bigcup_{s=1}^{r(i)} f_{j s, k s}\left({ }^{i n} S M^{j s}, k s\right),
\end{gathered}
$$

where ${ }^{\text {in }} S M^{\mathrm{js}, \mathrm{ks}}$-a subset ks of the components of a document ${ }^{\mathrm{in}} \mathrm{M}_{\mathrm{js}}, \mathrm{f}_{\mathrm{js}, \mathrm{ks}}$ - document processing rule ${ }^{\mathrm{in}} \mathrm{SM}^{\mathrm{js}, \mathrm{ks}}$, r(i) - the number of combining documents.

In the process of management activities in the divisions of the enterprise, some documents are subject to analysis, while others are synthesized, and unevenly. In order to have more complete understanding of the mechanism of information processing in the management process, general model of analysis and synthesis of several documents is proposed. Such model is described by the set of ${ }^{\text {in }} M=\left\{{ }^{\text {in }} M_{1},{ }^{\text {in }} M_{2}, \ldots,{ }^{\text {in }} M_{i}, \ldots,{ }^{\text {in }} M_{n}\right\}$ input documents, a set ${ }^{\text {out }} \mathbf{M}=\left\{{ }^{\text {out }} \mathrm{M}_{1},{ }^{\text {out }} \mathrm{M}_{2}, \ldots,{ }^{\text {out }} \mathrm{M}_{\mathrm{i}}, \ldots,{ }^{\text {out }} \mathrm{M}_{\mathrm{m}}\right\}$ of output documents, set ${ }^{\mathrm{in}} \mathrm{t}=\left\{{ }^{\mathrm{in}} \mathrm{t}_{1},{ }^{\mathrm{in}} \mathrm{t}_{2}, \ldots,{ }^{\mathrm{in}} \mathrm{t}_{\mathrm{i}}\right.$, $\left.\ldots,{ }^{i n} t_{n}\right\}$ of input analysis operators, set ${ }^{\text {out }} t=\left\{{ }^{\text {out }} t_{1},{ }^{\text {out }} t_{2}, \ldots,{ }^{\text {out }} t_{i}, \ldots,{ }^{\text {out }} t_{m}\right\}$ of output synthesis operators, as well as the matrix A of the interrelations of the analysis and synthesis operators Each line of such a matrix is a subset of the components of the input documents (grouped in relation to the analysis operators), that is, each line contains a logically indivisible an independent component of data used in the further processing or permanently stored in the system. The column of this matrix is the document synthesis operator and is a synthesized document that has already been processed at this stage of the system. Thus, the matrix A consists of $r=r(1)+\ldots+r(i)+\ldots+r(n)$ of the rows and $m$ columns. The element $a_{i j}$ of the matrix A equals one if the i-th row represents a subset of the constituent parts of the input document that is part of the source document that forms the $\mathrm{j}$-synthesis statement ${ }^{\text {out }} \mathrm{t}_{\mathrm{j}}$. Otherwise, the element is zero.

Thus, the matrix $\mathrm{A}$ is an incident matrix for some transition $\mathrm{t}$, which simulates a division of an enterprise where information processing takes place. For the sake of a single model, the set ${ }^{i n} t$ of of the analysis operators and the set ${ }^{\text {out }} t$ of the synthesis operators can be combined into a single operator $t={ }^{i n} t{ }^{\text {out }} t$ of document processing and graphically submit the operator $t$ as a macro transition of the Petri network.

Such transition is a set of rules for converting documents to a certain stage of their processing in any organizational unit. Formally, by defining the rule of converting data at each stage of their processing, you can get a complete set of data for a specific subdivision: inputs that remain on the storage, and those that transferred to other system elements. All lines of matrix A will be a set of input data: lines with all zeroes means that at this stage they complete their processing and remain in storage, and the rows whose elements are equal to 1, at least in one column, are output data. In addition, this model allows you to limit the amount and information set of documents processed at each stage. Rules $f_{i}$ determine the possibility of synthesis of a document and allow limit the set of synthesized documents.

Using macro transitions, one can build a model of any complex process of document processing. The simulated document processing model allows analysts to trace the flow of information in a system with varying degree of detailization. In particular, it can be concluded that there is duplication of information and excess information in divisions.

In this investigation it is important to consider the process of identifying and eliminating duplication of information in the system. In general, let for all documents $t$ - is an operator of processing of several documents, which has the form:

$$
\mathrm{t}\left(\left({ }_{1}{ }_{1},{ }_{2}, \ldots,{ }^{\text {in }} \mathrm{M}_{\mathrm{i}}, \ldots,{ }^{\text {in }} \mathrm{M}_{\mathrm{n}}\right)=\left({ }^{\text {out }} \mathrm{M}_{1},{ }^{\text {out }} \mathrm{M}_{2}, \ldots,{ }^{\text {out }} \mathrm{M}_{\mathrm{i}}, \ldots,{ }^{\text {out }} \mathrm{M}_{\mathrm{m}}\right) .\right.
$$

If ${ }^{\text {in }} \mathrm{M}_{\mathrm{i}}={ }^{\mathrm{in}} \mathrm{M}_{\mathrm{j}}$ or ${ }^{\text {out }} \mathrm{M}_{\mathrm{i}}={ }^{\text {out }} \mathrm{M}_{\mathrm{j}}$ for $\mathrm{i} \neq \mathrm{j}$, then the process of processing documents uses information that is duplicated in ${ }^{\text {in }} M_{i}$ and ${ }^{\text {in }} M_{j}$ or ${ }^{\text {out }} M_{i}$ and ${ }^{\text {out }} M_{j}$ respectively. This analysis relates to a part of a document. It can be carried out for all information in macro transition, for information in one direction, etc. Details of the can be selected by an analyst in the process of system implementation.

If duplication of information is found during the synthesis of documents, this may indicate of input data duplication. 
The next stage in the analysis of the information processing system is the discovery of non-processed information. For example, $t$ is the operator of the synthesis of the document $\mathrm{M}$ defined in formulas (3) and (4).. In ideal document circulation system all incoming documents $M_{i}$ must be converted to the rule $f_{i}$, i.e. $\mathrm{f}_{\mathrm{i}}\left(\mathrm{M}^{\mathrm{i}}\right) \neq \mathrm{M}^{\mathrm{i}}$ for $\mathrm{f}_{\mathrm{i}} \neq$ const $(\mathrm{i}=1, \ldots, \mathrm{r})$. Conversely, in a document circulation system that has gaps, all incoming documents can not be processed, i.e. $f_{i}\left(M^{i}\right)=M^{i}$ for $f_{i}=$ const $(i=1, \ldots, r)$., The rule $f_{i}$ can be denoted as data aggregation of several elements of the document, and complex transformations. It is common situation, when some documents can not be rearranged, and some can be changed according to the relevant rules. Formally, the document circulation system can be described as follows.

We use some definitions: by $\mathrm{I}=\{1,2,3, \ldots, \mathrm{r}\}$ we define the set of document numbers used when compiling the document $M ; I_{f} \subset I$ means a subset of the numbers of converted documents for which $f_{i} \neq$ const; $I_{c} \subset I\left(I_{f} \cup I_{c}=\right.$ I) represent a subset of non-processed document numbers for which $f_{i}=$ const. Proceeding from the proposed notation, the operator $\mathrm{t}$ of the synthesis of the document $\mathrm{M}$ can be described as:

$$
\begin{aligned}
& t\left(M^{1}, M^{2}, \ldots, M^{i}, \ldots, M^{r}\right)=M, \\
& M=\left(\bigcup_{i \in I_{f}} f_{i}\left(M^{i}\right)\right) \cup\left(\bigcup_{i \in I_{c}} M^{i}\right) .
\end{aligned}
$$

The essence of further analysis of the document circulation model is the removal of duplicate and not processed flows of information.

For example, when synthesizing an output document ${ }^{\text {out }} \mathrm{M}_{\mathrm{i}}$, duplicate information is found, ie if $\mathrm{q} \neq \mathrm{s}$

$$
\begin{aligned}
& { }^{\text {out }} t_{\mathrm{i}}\left({ }^{\mathrm{in}} \mathrm{SM}^{\mathrm{j} 1, \mathrm{k} 1}, \ldots,{ }^{\mathrm{in}} \mathrm{SM}^{\mathrm{jq}, \mathrm{kq}}, \ldots,{ }^{\mathrm{in}} \mathrm{SM}^{\mathrm{js}, \mathrm{ks}}, \ldots,{ }^{\mathrm{in}} \mathrm{SM}^{\mathrm{jr}(\mathrm{i}) \mathrm{kr}(\mathrm{i})}\right)={ }^{\text {out }} \mathrm{M}_{\mathrm{i}}, \\
& { }^{\mathrm{in}} \mathrm{SM}^{\mathrm{jq}, \mathrm{kq}}={ }^{\mathrm{in}} \mathrm{SM}^{\mathrm{js}, \mathrm{ks}}
\end{aligned}
$$

then one of subsets ${ }^{\mathrm{in}} \mathrm{SM}^{\mathrm{jq}, \mathrm{kq}}$ or ${ }^{\mathrm{in}} \mathrm{SM}^{\mathrm{j} s \mathrm{ks}}$ an be removed from the review, and the corresponding position and arc are removed from the model. Given that the subset of ${ }^{\text {in }} \mathrm{SM}^{\mathrm{jq}, \mathrm{kq}}$ is an integral part of the ${ }^{\mathrm{in}} \mathrm{M}_{\mathrm{jq}}$ document, and the position corresponding to the document ${ }^{i n} \mathrm{SM}^{\mathrm{jq}, \mathrm{kq}}$, has already been removed from the model, then the arc, that connect the transition that simulates the ${ }^{\text {in }} \mathrm{M}_{\mathrm{jq}}$ document analysis process with the removed position also must be removed (Fig. 2).

In the process of duplication detecting during synthesis of output documents, it may turn out that no one component of the ${ }^{\text {in }} M_{i}$ will be used in the synthesis of source documents. Then it can be removed from the model (Fig. 3).

From this it follows that when detecting duplication during synthesizing of output document ${ }^{\text {out }} \mathrm{M}_{\mathrm{i}}$, the question of removing duplicated documents ${ }^{\text {in }} \mathrm{SM}^{\mathrm{jq}, \mathrm{kq}}$ or ${ }^{\mathrm{in}} \mathrm{SM}^{\mathrm{j}, \mathrm{ks}}$ needs careful consideration. Properly planned work will help to identify an unnecessary input document in time.

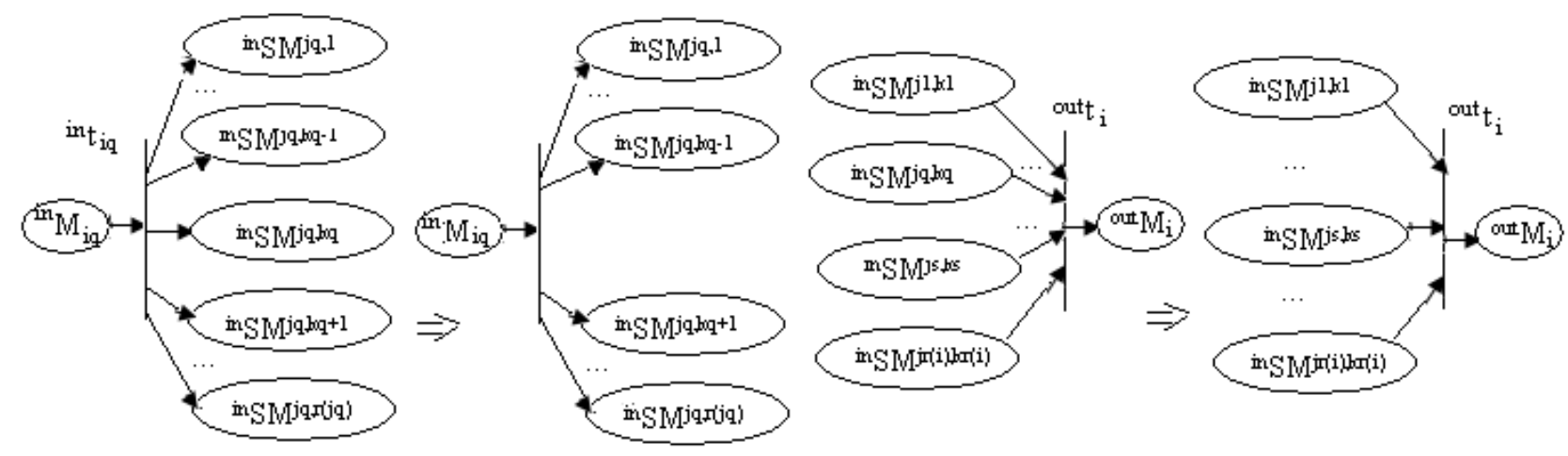

Figure 2. Removing a duplicate information flow 
It is advisable to first mark all pairs of duplicate documents. If all the components of input document ${ }^{\mathrm{in}} \mathrm{M}_{\mathrm{i}}$ are marked, it is necessary to remove the same document from all pairs. Next, it is possible situation, when removed input document ${ }^{i n} \mathrm{M}_{\mathrm{i}}$ is output document. This means that the corresponding synthesis operation for this document can be removed from the model. The elimination of synthesis operation is associated with subsequent transformations of the model, which are similar to those that were carried out in identifying duplication of information at the stage of document synthesis.

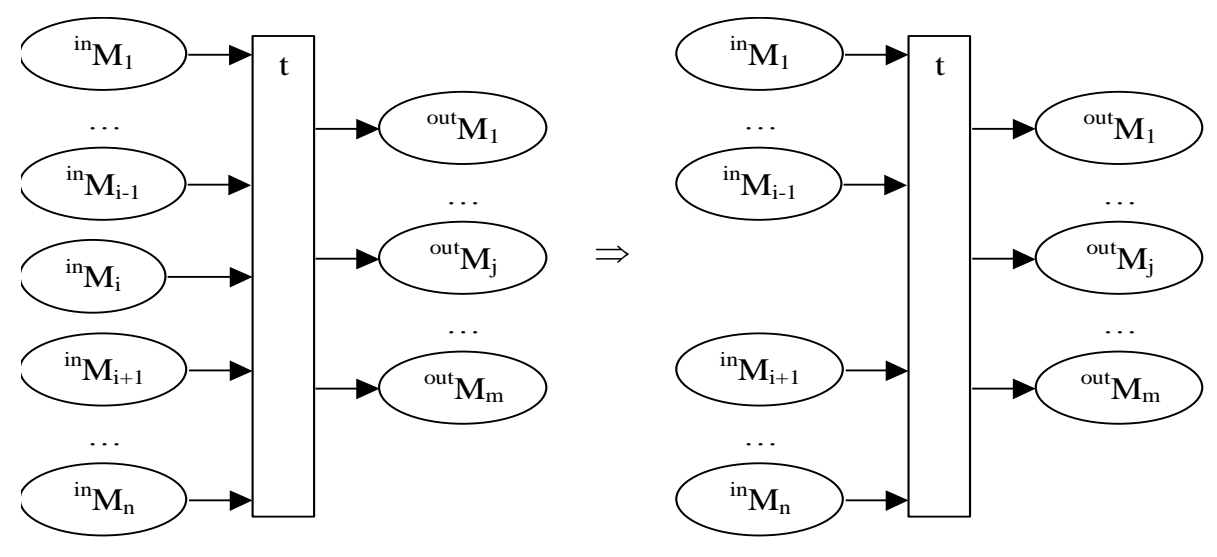

Figure 3. Removing a duplicate document

The next stage of transformation is the redistribution of non-processed information flows. Let ${ }^{\text {out }} t_{i}-$ synthesize operator of output document ${ }^{\text {out }} \mathrm{M}_{\mathrm{i}}$ :

$$
\begin{gathered}
\left.{ }_{\mathrm{t}_{\mathrm{i}}}{ }^{\mathrm{in}} \mathrm{SM}^{\mathrm{j} 1, \mathrm{k} 1}, \ldots,{ }^{\mathrm{in}} \mathrm{SM}^{\mathrm{j} \mathrm{s}, \mathrm{ks}}, \ldots,{ }^{\mathrm{in}} \mathrm{SM}^{\mathrm{jr}(\mathrm{i}), \mathrm{kr}(\mathrm{i})}\right)={ }^{\mathrm{out}} \mathrm{M}_{\mathrm{i}}, \\
{ }^{\text {out }} \mathrm{M}_{\mathrm{i}}=\left(\bigcup_{s=1}^{s(i)} f_{j s, k s}\left({ }^{i n} S M^{j s, k s}\right)\right) \cup\left(\bigcup_{s=s(i)+1}^{r(i)} S M^{j s, k s}\right) .
\end{gathered}
$$

To streamline information flows at article we propose to renumber incoming documents: documents with numbers from 1 to $s$ (i) will be changed, and documents with numbers from s (i) +1 to $r(i)$ will remain unchanged. (Fig. 4).

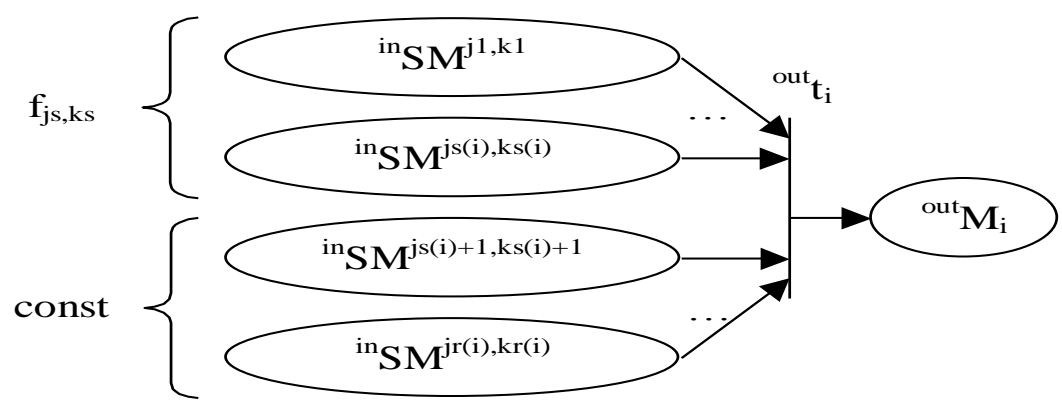

Figure 4. Model of document synthesis in relation processed arrays

If for some input document ${ }^{\text {in }} \mathrm{M}_{\mathrm{i}}$ it appears that all its constituent parts remain unchanged in the output documents, then this document should not be submitted to the input of the operator $t$, but immediately passed it to the input of the corresponding operators (Fig. 5).

After removing of duplicated and non-processed documents, it is necessary to determine the division (organizational unit, department or individual person) to whom documents will be sent. To do this, it is 
necessary to define and assign information functions to divisions and formalize them taking into account the rules for processing documents.

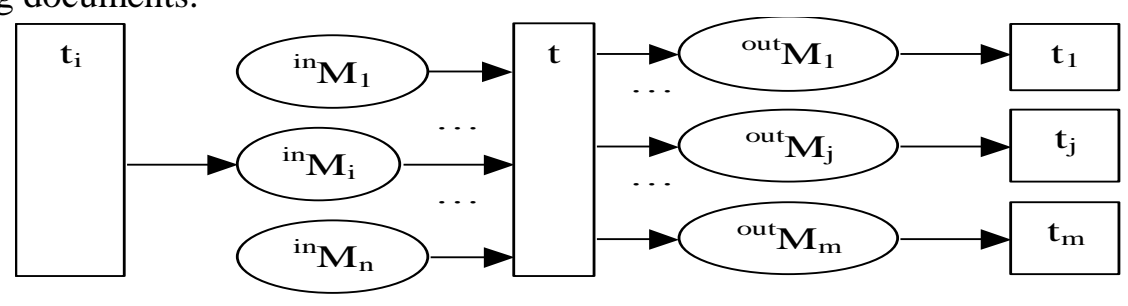

$\Downarrow$

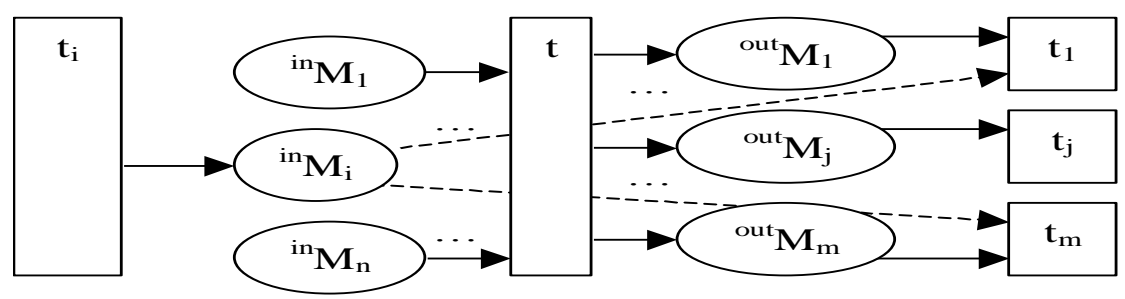

Figure 5. Removing non-processed information

Denote by $\mathrm{F}$ the set of all rules for processing documents in the document management system $\mathrm{S}$ such that the set $\mathrm{F}$ is a complete set of formalized rules for processing documents in an organization. In this case, it can be divided into disjoint subsets $F_{i}(i=1, \ldots, m)$ of the same type rules, where each $F_{i}$ subset characterizes the processing rules for individual functional or process areas of the organization's activities, i.e. in the subsystems of $S_{i}$ document flow. And for them the following is true:

$$
F=\bigcup_{i=1}^{m} F_{i}, \text { where } F_{i} \cap F_{j}=\varnothing \text { при } i \neq j
$$

Let Ft denote the set of all the rules for processing documents by the transfer of the Petri net, obtained after eliminating duplicated and non-processed information flows, i.e. $\mathrm{F}^{t}$ is a set of rules for processing documents in a separate division. In accordance with the rules of linear algebra by $|\mathrm{A}|$ we will denote the number of elements in the set A.

To determine the extent to which the processing rules of the documents actually go in the subdivision of its main functions (according to departmental or other documents, informal distribution) for each transition $\mathrm{t}$, we enter the measure ${ }^{t} \mu_{i}$ of its specificity for $S_{i}$ subsystem as follows:

$$
{ }^{\mathrm{t}} \mu_{\mathrm{i}}=\frac{\left|\mathrm{F}^{\mathrm{t}} \cap \mathrm{F}_{\mathrm{i}}\right|}{\left|\mathrm{F}_{\mathrm{i}}\right|} \text {. }
$$

The measure of the characteristicity of document processing for the $S_{i}$ document circulation subsystem is determined by the number of general rules for processing documents by this subdivision and the rules specific to this subsystem. A quantitative assessment of the degree of compliance is interpreted such:

- if ${ }^{\mathrm{t}} \mu_{\mathrm{i}}=1$, the subdivision fully corresponds with the document circulation subsystem $S_{\mathrm{i}}$. This means that organizational unit, modeled by this transition, works in accordance with the information flow distribution subsystem and must be included in the S subsystem;

- if ${ }^{\mathrm{t}} \mu_{\mathrm{i}}=0$, the subdivision is absolutely unrelevant for the $S_{\mathrm{i}}$ subsystem when processing documents. This means that organizational structure, modeled by this transition of Petri Net, cannot be included in the subsystem $S_{\mathrm{i}}$;

- if $0<{ }^{\mathrm{t}} \mu_{\mathrm{i}}<1$, transition $t$ can be attributed to the subsystem $\mathrm{S}_{\mathrm{i} 0}$ for which the measure of specificity is higher: 


$$
\mathrm{t} \in \mathrm{S}_{\mathrm{i} 0} \Leftrightarrow{ }^{\mathrm{t}} \mu_{\mathrm{i} 0}=\max _{\mathrm{i}=1, \ldots, \mathrm{m}}{ }^{\mathrm{t}} \mu_{\mathrm{i}} .
$$

However, the proposed technique has some problem: what to do if the maximum is reached for several subsystems? For example, with ${ }^{\mathrm{t}} \mu_{\mathrm{i} 0}={ }^{\mathrm{t}} \mu_{\mathrm{i} 1}=\max _{\mathrm{i}=1, \ldots, \mathrm{m}} \mu_{\mathrm{i}}^{\mathrm{t}}$ which subsystem refers an organizational structure modeled by the transition t: to the subsystem $\mathrm{S}_{\mathrm{i} 0}$ or $\mathrm{S}_{\mathrm{i} 1}$ ?

In this case, we propose the following recommendation: divide the organizational structure, modeled by this transition into two: one attributed to the subsystem $S_{\mathrm{i} 0}$, and other - to $S_{\mathrm{i} 1}$, and if this solution is not satisfactory, then it should be considered from organizational rules point of view.

It can be noted that even if the maximum is reached for one subsystem, this maximum can be quite small (for example, equal to 0.2). This indicates an extremely unsuccessful organizational structure that needs reorganization, since the difference between subsystems of enterprise information flows and systems of organizational management is too large.

It is also possible case, when for a particular $F_{1}$ subsystem the set of rules consists of 10 and the degree of compliance is ${ }^{t} \mu_{1}=0,9$, while for another subsystem $F_{2}$, the set of rules consists of $100,{ }^{t} \mu_{2}=0,85$. This means that subsystem $S_{1}$ is characterized by 10 rules, 9 of which are carried out by the organizational unit t, and subsystem $S_{2}$ is characterized by 100 rules, 85 of which are executed by the organizational unit t. In this case, in accordance with the rule on formula (19), the organizational unit $t$ is recommended to refer to the subsystem $S_{1}$. In this case, the partitioning of the system $S$ into subsystems should be more uniform. You can not "dump" most of the system on some subsystems.

After combining organizational structures into subsystems, two organizational structures (for example, $\mathrm{t} 1$ and t2) can perform several identical functions of this subsystem $\left(\mathrm{F}^{\mathrm{t} 1} \cap \mathrm{F}^{\mathrm{t}} \neq \varnothing\right.$ for $\left.\mathrm{t}_{1} \neq \mathrm{t}_{2}\right)$. Here you can split the subsystem into the corresponding subsystems (they will be sub-subsystems), carry out organizational transformations from the very beginning, but at a lower level.

\section{Conclusions}

On this way the methodology of document circulation processes and organizational transformations on the basis of divisions' information links is approved.

The usage of proposed approach for Electricity Delivery company PJSC "Kharkivoblenergo" (Kharkiv, Ukraine) resulted in significant reduction of the document circulation (about 11\%), the establishment of the correspondence of information flows to the purpose and functions of the divisions, the increase of the adequacy of the actions of the subsystem, which governs the state of the management.

Proposed investigations can be further developed by business process modeling technique, which will make it possible to simulate a sequence of single document processing operations and make more clear the links between individual workplaces, and in general between divisions.

\section{Abbreviations and Acronyms}

$\begin{array}{ll}\% & \text { percentage } \\ \text { BPMN } & \text { Business Process Modeling Notation } \\ \text { Fig. } & \text { Figure } \\ \text { Et. al. } & \text { etc. } \\ \text { i.e. } & \text { in other words } \\ \text { PJSC } & \text { Public Joint Stock Company }\end{array}$

\section{Acknowledgements}

This paper was created at the Department of Economic Cybernetics and Management of Economic Security, Kharkiv National University of Radio Electronics Kharkiv, Ukraine. The Authors express their gratitude to the Management of Public Joint Stock Company "Kharkivoblenergo", Kharkiv, Ukraine, for providing necessary data to complete this study successfully. 


\section{References}

[1] C. Durungo, A. Tiwari, J.R. Alcock "Modelling Information Flows for Organizations: a Review of Approaches and Future Challengers," International Journal of Information Management, vol. 33, pp.597610, 2013

[2] P.Baldan, A. Beggiato, A.L. Lafuente "Many-to-many Information Flow Policies. Lecture Notes in Computer Science," 10319 LNCS, pp. 159-177, 2017

[3] P.P. Sengupta, M.Sinha, U.P. Dutta "Economic and environmental performances in manufacturing industries: A comparative study," Periodicals of Engineering and Natural Sciences Vol. 7, No. 1, pp.99108,2019

[4] M. A. Moisescu, I. S. Sacala, I. Dumitrache, S. I. Caramihai, B. Barbulescu, M. Danciuc "A cyberphysical systems approach to cognitive enterprise," Periodicals of Engineering and Natural Sciences, vol. 7, no. 1, pp.337-342, 2019

[5] V.Babenko, N.Chebanova, N. Ryzhikova, S.Rudenko, N.Birchenko, "Research into the Process of Multilevel Management of Enterprise Production Activities with Taking Risks into Consideration," EasternEuropean Journal of Enterprise Technologies, vol. 1, No 3 (91), pp. 4-12, 2018

[6] V. Babenko, O. Nazarenko, I. Nazarenko, O. Mandych "Aspects of program control over technological innovations with consideration of risks", Eastern-European Journal of Enterprise Technologies, vol. 3/4 (93), pp. 6-14, 2018.

[7] J. Desel, A. Oberweis, W. Reisig, G. Rozenberg "Petri Nets and Business Process Management,", Dagstuhl seminars. Tech report, 1998

[8] C.A. Petri "Fundamentals of a Theory of Asynchronous Information Flow", in IFIP Congress 62, Munich, Germany, August 27 - September 1, 1962, pp.386-390, 1962

[9] C.A. Petri "Communication with Automata", DTIC Research Report AD0630125, 1966

[10] F. Cheng, H. Li, Y.W. Wang, M. Skitmore, P. Forsythe "Modeling Resource Management in the Building Design Process by Information Constraint Petri Nets," Automation in Construction, vol. 29, pp. 92-99, 2013

[11] F. Ma, J.Wang "Modeling and Simulation Method of Enterprise Energy Consumption Process Based on Fuzzy Timed Petri Nets," in 7th World Congress on Intelligent Control and Automation.2008 WCICA '08, pp. 4148-4152, 2008

[12] A. Tuma "Energy and Material Management Based on a Fuzzy Petri Net Approach," International Journal of Environment and Sustainable Development, vol. 1, no. 2, pp.160-170, 2002

[13] W.C.H. Schoonenberg, A.M. Farid "A Dynamic Model for the Energy Management of Microgridenabled Production Systems," Journal of Cleaner Production, vol. 164, pp.816-830, 2017

[14] M. Karabulut "Application of Monte Carlo simulation and PERT/CPM techniques in planning of construction projects: A Case Study," Periodicals of Engineering and Natural Sciences, vol.5, No.3, pp. 408- 420, 2017

[15] A.Yadav, S.C.Jayswal "Modelling of Flexible Manufacturing System: a Review," International Journal of Production Research, 56, vol. 7, 2464-2487, 2018

[16] M. Narciso, M.A.Piera "Modeling Discrete Event Systems Using Petri Nets," in Robust Modelling and Simulation: Integration of SIMIO with Coloured Petri Nets , pp. 49-85, 2017

[17] J.C.J. Freitas, S. Julia, L.P. de Rezende "Resource Allocation Mechanisms and Time Constraint Propagation Techniques in Fuzzy Workflow Nets," Lecture Notes in Business Information Processing, vol. 241, pp. 214-235, 2015

[18] D. Pramod, S.V. Bharathi "Developing an Information Security Risk Taxonomy and an Assessment Model Using Fuzzy Petri Nets," Journal of Cases on Information Technology, vol. 20, issue 3, pp. 48-69, 2018

[19] A. Bozek, M. Wysocki, "Off-line and dynamic production scheduling - A comparative case study," Management and Production Engineering Review, vol. 7, issue 1, pp. 21-32, 2016

[20] S.Rudel, M. Schimmel, S.Zelewski "Process Simulation for Small and Medium-sized Enterprises", Productivity Management, vol. 22, issue 1, pp. 433-442, 2017

[21] M.Tu, M.K. Lim, M.F.Yang "IoT-based Production Logistics and Supply Chain System," Industrial Management and Data Systems, vol. 118, Issue 1, pp. 2018: 65-95, 2018

[22] D. Panchal, D. Kumar "Stochastic Behaviour Analysis of Real Industrial System," International Journal of Systems Assurance Engineering and Management, vol. 8, pp.1126-1142, 2017 
[23] R. Kim, J. Gangolly, P. Elsas "A Framework for Analytics and Simulation of Accounting Information Systems: A Petri Net Modeling Primer," International Journal of Accounting Information Systems, vol. 27, pp. 30-54, 2017

[24] G.Yasuda "Modeling and Control of Production Task Flows Using High-level Activity-based Petri Nets," in Handbook of Research on Design and Management of Lean Production Systems, pp.115-128, 2014

[25] J.B. Linn III "Reverse-engineering the business cycle with Petri nets," Journal of Business Cycle Measurement and Analysis, vol. 2015/2, pp. 1-28, 2015

[26] Lv.Yaqiong, D.Lin "Design an intelligent real-time operation planning system in distributed manufacturing network," Industrial Management \& Data Systems, vol. 117, issue 4, pp. 742-753, 2017

[27] X.Ye, X.Bian, Q. Xu "Empirical Analysis and Optimization for Supply Chain Finance Business Process Based on Petri Nets," in Proc. 15th International Conference on Service Systems and Service Management ICSSSM'18, 2018

[28] P. Tulinayo, S. Hoppenbrouwers, P.V. Bommel, H.A. Proper "Integrating System Dynamics with ObjectRole Modeling and Petri Nets," EMIS, 2009

[29] H.Ullah "A Petri Net Model for the Integration of Purchasing, Production and Packaging Using Kanban System," Advances in Production Engineering And Management, vol. 9(4), pp. 187-200, 2014

[30] Zhou "Petri-net Based Safety Analysis of Process Systems," in IEEE International Conference on Industrial Engineering and Engineering Management, Singapore; December 10-13, 2017

[31] A. Lyazidi, S. Mouline "A Model-driven Engineering Approach to Formally Verify BPMN Models Using Petri Nets," International Journal of Business Process Integration and Management, vol. 8, issue 4, pp. 273-284, 2017

[32] D.A. Karras, R.C.Papademetriou "A Systematic Review of Analytical Management Techniques Applied to Competition Analysis Modeling towards a Framework for Integrating them with BPM," in $7^{\text {th }}$ International Symposium on Business Modeling and Software Design, BMSD'17, 2017

[33] T. Murata "Petri Nets: Properties, Analysis and Applications", in IEEE, 77, April: 541-580, 1989

\section{Bibliography of authors}

\begin{tabular}{l} 
Kyriy, V. PhD (Economics Sciences), Associate Professor, Kharkiv National University of Radio \\
Electronics, Associate Professor at the Department of Economic Cybernetics and Management of \\
Economic Security, Kharkiv, Ukraine \\
e-mail: valentyna.kyriy@nure.ua \\
$\begin{array}{l}\text { Sheiko, I. PhD (Economics Sciences), Associate Professor, Kharkiv National University of Radio } \\
\text { Electronics, Associate Professor at the Department of Economic Cybernetics and Management of } \\
\text { Economic Security, Kharkiv, Ukraine } \\
\text { e-mail: irina.sheiko@nure.ua } \\
\text { Petrova, R. PhD (Engineering Sciences), Associate Professor, Kharkiv National University of Radio } \\
\text { Electronics, Associate Professor at the Department of Economic Cybernetics and Management of } \\
\text { Economic Security, Kharkiv, Ukraine } \\
\text { e -mail: roksana.petrova@nure.ua }\end{array}$ \\
\hline
\end{tabular}

